\title{
Sex-Gender Differences in the Effectiveness of Treatment of Irritable Bowel Syndrome: A Systematic Review
}

This article was published in the following Dove Press journal: International Journal of General Medicine

\section{Lente van Kessel (iD Doreth Teunissen (iD \\ Toine Lagro-Janssen (D)}

Department of Primary and Community Care / Gender and Women's Health, Radboud University Medical Centre, Nijmegen, the Netherlands
Correspondence: Lente van Kessel Multatuliplaats I8A, Nijmegen, 653IDW, the Netherlands

$\mathrm{Tel}+3 \quad$ I68 I47 3355

Email Lentevkessel@gmail.com
Background: In recent years, research on sex-gender differences in health care has increasingly recognized that men and women differ in the way symptoms occur, in risk factors for certain conditions and in the way they respond to the same treatment. A disease that is known to often present differently in women and men is irritable bowel syndrome (IBS). Given the difference in prevalence, predominant symptoms and possible other pathophysiology, it is conceivable that a difference in treatment effectiveness in men and women is a discovery waiting to be found.

Purpose: To determine whether there are differences in treatment effectiveness between men and women with irritable bowel syndrome.

Materials and Methods: We searched on PubMed and EMBASE, selecting randomized controlled trials comparing IBS treatment in men and women over 18 years old. One researcher performed the inclusion process, and two researchers independently performed a quality assessment. A descriptive analysis was conducted.

Results: Twelve studies, randomizing 1847 men and 3562 women, were included in this review. Treatment with serotonin antagonist alosetron, treatment with ibodutant and crofelemer and adding cognitive behavioral therapy to medical treatment found significant differences between men and women in favor of effectiveness towards women in either satisfactory relief of overall IBS symptoms or percentage of pain-free days.

Conclusion: Sex-gender can be a determining factor in the effectiveness of IBS treatment. Due to the limited number of studies per treatment option, no recommendations can be made on the choice of a specific treatment. It is clear, however, that so as not to miss beneficial treatment options for either sex, the inclusion, analysis and description of data on the basis of sex is of the utmost importance.

Keywords: colonic diseases, abdominal pain, randomized controlled trials, male, female, treatment

\section{Introduction}

Irritable bowel syndrome (IBS) is a chronic gastrointestinal (GI) disorder, characterized by recurrent abdominal pain and altered bowel movements. ${ }^{1}$ The main symptoms are constipation, diarrhea, bloating or pain, which seem to fluctuate in intensity and duration over time. ${ }^{2}$ IBS is diagnosed clinically, based on the Rome diagnostic criteria (Appendix 1), physical examination and limited diagnostic tests. IBS is one of the most common GI disorders, accounting for $12 \%$ of all primary care visits, and is the most common reason for visiting the gastroenterologist. 
Patients with IBS report that it substantially reduces their quality of life and work productivity., ${ }^{2,3}$ IBS affects both men and women, but the prevalence of IBS is higher in women than in men, with an odds ratio of $1.67 .{ }^{4}$ Men and women appear to experience different symptoms to be the most bothering and may react differently to treatment. IBS with constipation (IBS-C) is significantly more common in women, whereas IBS with diarrhea (IBS-D) is more common in men. ${ }^{5}$

There are many theories to explain these differences. It can partly be explained by a variety of sex- and genderrelated biological and psychosocial factors. ${ }^{5}$ Since several studies have shown that there is an effect of sex hormones, especially estrogen and progesterone, on bowel function, gastrointestinal transit time and the processing of pain stimuli in the central nervous system, it is conceivable that this system may be related to the greater prevalence of functional syndromes in women. ${ }^{6}$ Whilst recurring pain and discomfort in the pelvic region is quite familiar to women, moreover, it is a rare experience for men. Women, therefore, might be more vigilant toward sensory stimuli from the pelvic area and are also able to discriminate between physiological discomfort and potentially noxious events. ${ }^{5}$ In addition, it is becoming evident that the gastrointestinal tract microbiota differ in males and females. ${ }^{7}$ Likely causes include differing sex hormone levels in males and females, in part driven by sex differences in systemic sex hormone concentrations but also influenced by microbiota themselves. A different microbiota composition drives sex differences in innate and adaptive immunity, which might lead to sex-dependent susceptibility to IBS. This sexually dysmorphic microbiome has been termed the "microgenderome.",

Besides different underlying pathophysiology mechanisms, another reason for male and female patients to require different treatments is a difference in response to drugs. As knowledge of medicinal drug toxicology and pharmacology is expanding, it has become clear that men and women react differently to drug treatments due to physiological differences such as body weight and length, total body water, extra- and intracellular water and surface area, as well as differences in pharmacodynamics and pharmacokinetics. ${ }^{8}$ As IBS is a prevalent yet heterogeneous disorder, patient selection for a given treatment can be challenging and, considering the underlying mechanisms indicated above, may be influenced by a patient's sex or gender. ${ }^{9}$
"Sex" is commonly defined as the property or quality by which organisms are classified as female or male on the basis of biological, that is chromosomal and hormonal, characteristics, whereas "gender" is understood in terms of masculinity and femininity, which are largely culturally determined. It is clear that sex and gender, though set apart as two concepts, are strongly intertwined in medicine, and they are used interchangeably in this study. ${ }^{10}$

The above-mentioned differences in pathophysiology might have implications for personalized treatment of IBS. It is of great importance to review what is known about differences in response to treatment in men and women with IBS. The main objective of our study, therefore, is to determine whether there are differences in treatment effectiveness between men and women with irritable bowel syndrome. This way we aim to provide tools for a wellconsidered personalized treatment of patients with IBS.

Table 1 shows a list of the most commonly used abbreviations in this article.

\section{Materials and Methods Data Sources and Study Selection}

We conducted a broad search on PubMed and EMBASE. With the assistance of a professional librarian, a search strategy was set up with combined MeSH terms and free text terms in order to build a broad discovery net for articles on IBS and these terms: sex, sexism, gender (identity), difference man/women, treatment, disease management, therapy or pharmacology (Table 2). After this search had been executed, studies were loaded in Endnote X9 to delete duplicates. A random sample of ten meta-analyses was examined to determine if they yielded any new RCTs that needed to be considered for inclusion. This was not the case. Studies were screened in title and abstract to ascertain: 1) whether the study was solely about IBS; 2) whether both men and women were included; and 3) whether the study was a randomized controlled trial. Articles were considered eligible for inclusion when they met the following criteria: 1) population included men and women over the age of 18 who were diagnosed with IBS; and 2) study analyzed men and women as two subgroups; and 3) the study was written in English. We have chosen to include only studies that look at the difference between men and women in the effectiveness of treatment. Studies that did not meet the inclusion criteria were excluded. 
Table I Meaning of Abbreviations from This Systematic Review

\begin{tabular}{|l|l|}
\hline Abbreviation & In Full \\
\hline 5-HT & Serotonin \\
AST & Spherical carbon adsorbent \\
BS-IBS & Behavior Scale for irritable bowel syndrome \\
CBT & Cognitive behavioral therapy \\
EMT & Emotional awareness and medical treatment \\
FDA & Food and Drug Administration \\
GI & Gastro-intestinal \\
GP & General practitioner \\
HADS & Hospital anxiety and depression scale \\
IBS & Irritable bowel syndrome \\
IBS-C & Constipation predominant irritable bowel syndrome \\
IBS-D & Diarrhea predominant irritable bowel syndrome \\
IBS-M & Mixed diarrhea and constipation irritable bowel syndrome \\
LBT & Lactulose breath testing \\
MT & Medical treatment \\
RCT & Randomized controlled trial \\
SIBO & Small intestine bacterial overgrowth \\
SSS & Symptom severity scale \\
VAS & Visual analogue scale (for pain measurement) \\
WASA & Work and social adjustment scale \\
\hline
\end{tabular}

\section{Quality Assessment}

The quality of the eligible studies was assessed by two independent researchers (LK, JW) using the Quality
Assessment of Controlled Intervention Studies (QACIS) tool by the National Institute of Health (Appendix 2). ${ }^{11}$ The advantage of this tool over other frequently used assessment tools, such as the Cochrane Risk of Bias Tool, is that it consists of specific yes-or-no questions on criteria that a study should meet. ${ }^{12}$ As a result, QACIS provides a clear dividing line between whether or not an RCT should be included.

Based on the QACIS tool, studies were categorized as POOR, FAIR or GOOD. If a "fatal flaw" was present, studies were instantly rated as POOR. Fatal flaws are high dropout rates, a small sample size and statistical power $<80 \%$, no intention-to-treat analysis or other unsuitable statistical analysis. Apart from these fatal flaws, assessment items that were considered to be of special importance to discriminate between studies of good, fair and poor quality were: 1) an adequate description of the randomization method; 2) the blinding of participants and providers; 3) the use of validated outcome measures; 4) the percentage of treatment adherence; and 5) similar baseline characteristics (Appendix 2). To differentiate between POOR, FAIR or GOOD (apart from fatal flaws), a rating scale was constructed, in which the above-mentioned

Table 2 Full Search Strategy

\begin{tabular}{|c|c|c|}
\hline Database & Search Strategy & Results \\
\hline Pubmed & $\begin{array}{l}\text { Intervention: "Colonic Diseases, Functional/therapy"[Mesh] OR Therapeutics [MesH] OR pharmacology [mesh] OR } \\
\text { disease management [mesh] OR gastrointestinal agents [mesh] OR "Gastrointestinal Agents" [Pharmacological Action] } \\
\text { OR therap* [tiab] OR therapeutic* [tiab] OR treatment* [tiab] OR pharmacolog* OR Disease Management* [tiab] OR } \\
\text { gastrointestinal Agent* [tiab] OR gastrointestinal drug* [tiab] OR gastric agent* [tiab] OR digestant* [tiab] } \\
\text { AND } \\
\text { Population: (“Colonic Diseases, Functional”[Mesh]) OR (continuous abdominal pain[tiab] OR continuous gastrointestinal } \\
\text { pain[tiab] OR frequent abdominal pain[tiab] OR frequent gastrointestinal pain[tiab] OR Functional abdominal pain [tiab] } \\
\text { OR Functional colon disease*[tiab] OR Functional colonic disease*[tiab] OR Functional colorectal disease*[tiab] OR } \\
\text { Functional gastrointestinal pain [tiab] OR Irritable bowel [tiab] OR Irritable Colon[tiab] OR Mucous Coliti*[tiab]) } \\
\text { AND } \\
\text { Population: "Sexism"[Mesh] OR "Sex Distribution"[Mesh] OR "Sex Factors"[Mesh] OR "Sex"[Mesh] OR "Sex } \\
\text { Characteristics"[Mesh] OR "Gender Identity"[Mesh] OR Sex[tiab] OR gender[tiab] OR sexism[tiab] OR (difference* } \\
\text { [tiab] AND (man[tiab] OR men[tiab] OR male*[tiab]) AND (woman[tiab] OR women[tiab] OR female*[tiab])) }\end{array}$ & 603 \\
\hline \multirow[t]{3}{*}{ EMBASE } & $\begin{array}{l}\text { Intervention: } \\
\text { Exp therapy/or treatment.mp. or exp pharmacology/or exp "ceiling effect (pharmacology)"/or disease management.mp. or } \\
\text { exp disease management } \\
\text { Population: } \\
\text { Irritable colon.mp. or exp irritable colon/ } \\
\text { exp gender identity/or "sex and gender".mp. or exp sex difference/or exp gender/or exp gender bias/or exp sexism/or sex } \\
\text { distribution.mp. or exp sex ratio/or exp sex factor/or Sex characteristics.mp. or exp sexual characteristics/ }\end{array}$ & 842 \\
\hline & & 1445 \\
\hline & une, 2020 & \\
\hline
\end{tabular}


assessment items were given 2 points, and the other items were given 1 point each. Cut-off points were discussed and determined, at $<11$ points as POOR, 11-16 as FAIR and $>16$ as GOOD. Whenever there was disagreement on certain aspects of the quality assessment of an article, a discussion with the supervising committee was held until consensus was reached.

\section{Data Extraction and Analysis}

Data were extracted on population and sample, type of intervention, primary and secondary outcome measures, and outcomes and data on male and female sub-groups, using a standardized extraction form. Whenever results were only presented in a graph, data were manually extracted by enlarging the graph to A3-size and estimating the outcomes. One study mentioned that no differences between men and women were found, but they did not show the subsequent data, so the authors were approached by e-mail to request additional data. Unfortunately, no response was given despite reminders. We performed a descriptive analysis of the included studies.

\section{Results}

The search resulted in a sample of 1445 studies (PubMed 603, EMBASE 842) (Figure 1 Prisma Flowchart), of which 1232 studies remained after removing duplicates. Out of these studies, 66 studies were considered potentially eligible after title/abstract screening. Reasons for excluding studies were study type, study population $(<18$ or only male/female patients included) or no mention of sex- and/or gender differences. Examination of the full text of the remaining studies led to the selection of 17 randomized controlled trials that met the inclusion criteria. After quality assessment, 12 studies, including 1847 men and 3562 women, remained to be included in our systematic review (Table 3). Appendix 3 provides the main characteristics of the studies excluded after quality assessment.

\section{Main Characteristics of Included Studies}

Almost all studies were placebo-controlled randomized trials. One study compared mebeverine with additional cognitive behavioral therapy to mebeverine alone. ${ }^{13}$ Most patients were diagnosed according to the current Rome criteria, and one study used GP diagnosis. Of 12 included studies, 4 included only IBS-D patients, and 2 included only IBS-C. The other 8 studies included all types of IBS: constipation dominant, diarrhea dominant or mixed. Studies were published between 1999 and 2019.

\section{Types of Interventions}

Intervention types can be divided into pharmaceutical interventions (Table 4), psychological interventions and alternative interventions (Table 5).

\section{Outcome Measures}

The primary outcome mostly assessed an adequate reduction of IBS symptoms as indicated by a reduction in the symptom severity scale; reduction in the sum of symptoms; self-reported adequate relief of symptoms; a composite responders score (experiencing a $\geq 30 \%$ reduction of their IBS-symptoms on more than half the days); increased number of pain-free days; improvement in stool consistency; or decreased VAS intensity of pain.

\section{Effects of Interventions}

\section{Pharmaceutical Interventions}

Table 4 shows the pharmaceutical interventions included in this systematic review, with a brief description of the agent studied. They have been ordered by type of pharmaceutical (either a serotonin antagonist or not), and within these subgroups, they have been ordered by their quality assessment score, starting with the highest scores.

\section{Serotonin Antagonists}

George et al studied renzapride. ${ }^{14}$ No significant differences were observed between male and female participants concerning adequate pain relief of abdominal pain/discomfort, and no significant response was reached in the overall population. The study was rated good (18/20). Ramosetron hydrochloride was studied by Matsueda et al. ${ }^{15}$ Comparing the differences in response between placebo and ramosetron, they found no significant differences between male and female patients. Both men and women showed comparable positive effect. The study was rated good (17/20).

Two studies with alosetron, Camilleri et al and Bardhan et al, showed comparable results concerning gender differences in the treatment of IBS. ${ }^{16,17}$ First, women reported to experience 12 more pain-free days in the last three weeks of treatment when receiving $2 \mathrm{mg}$ of alosetron compared to placebo, whereas in males there was no significant benefit with any dose of alosetron over placebo. Second, one and a half times as many women experienced an improvement in diarrhea comparing placebo to $2 \mathrm{mg}$ alosetron. This improvement was barely noticeable in men. Thirdly, almost twice as many women reported 


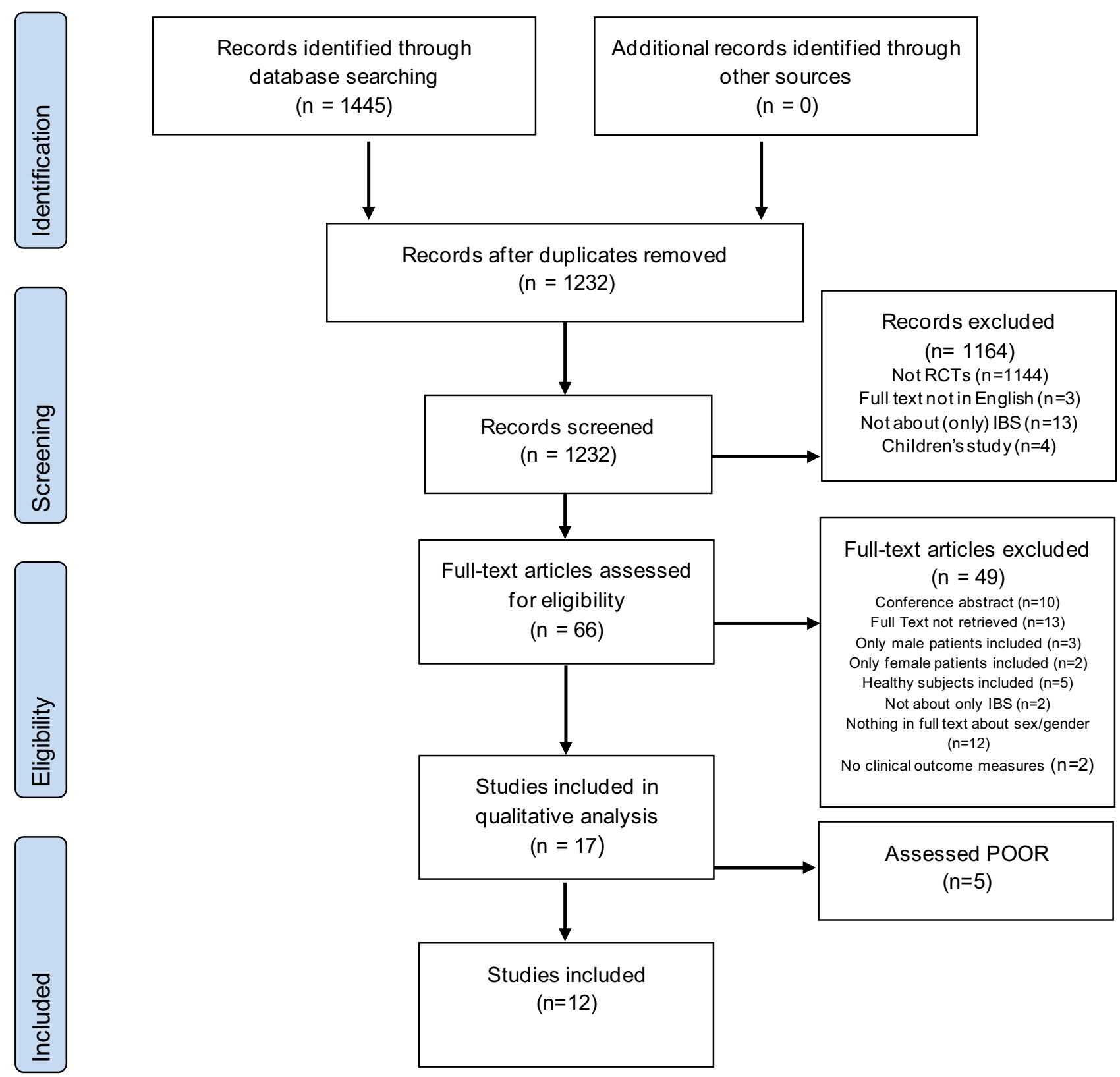

Figure I A flowchart of the selection of articles. In the first step of screening, most articles were rejected because they were not RCTs. Other reasons for exclusion were that they were not written in English, were not about (only) IBS or were children's studies. In the next step, where eligibility was considered based on the full text, an additional three-quarters of the articles were dropped for a variety of reasons: not discussing sex-gender differences was the most important (other reasons are mentioned in the figure itself). The remaining articles met all inclusion criteria and were scored for quality. The studies that scored fair/good on this were ultimately included in this review.

adequate relief of their IBS pain and discomfort receiving 1 or $2 \mathrm{mg}$ alosetron, whereas this barely improved in men. Camilleri et al reported significant improvement in urgency, hardened stool and decreased frequency in women, but not in men. Bardhan et al reported no significant improvement in either male or female patients concerning the improvement of VAS-score and frequency, with no differences between the groups. Stool consistency improved significantly in both males and females, with no significant difference between the groups. Studies were both rated fair (resp. 15/20 and 14/20).

\section{Other Pharmaceutical Interventions Ibodutant}

In the study of Tack et al, ibodutant 10mg demonstrated significant superiority over placebo in females. ${ }^{18}$ The percentage of satisfactory relief of overall IBS symptoms and abdominal pain doubled in women $(24.4 \%$ to $46.8 \%)$, 


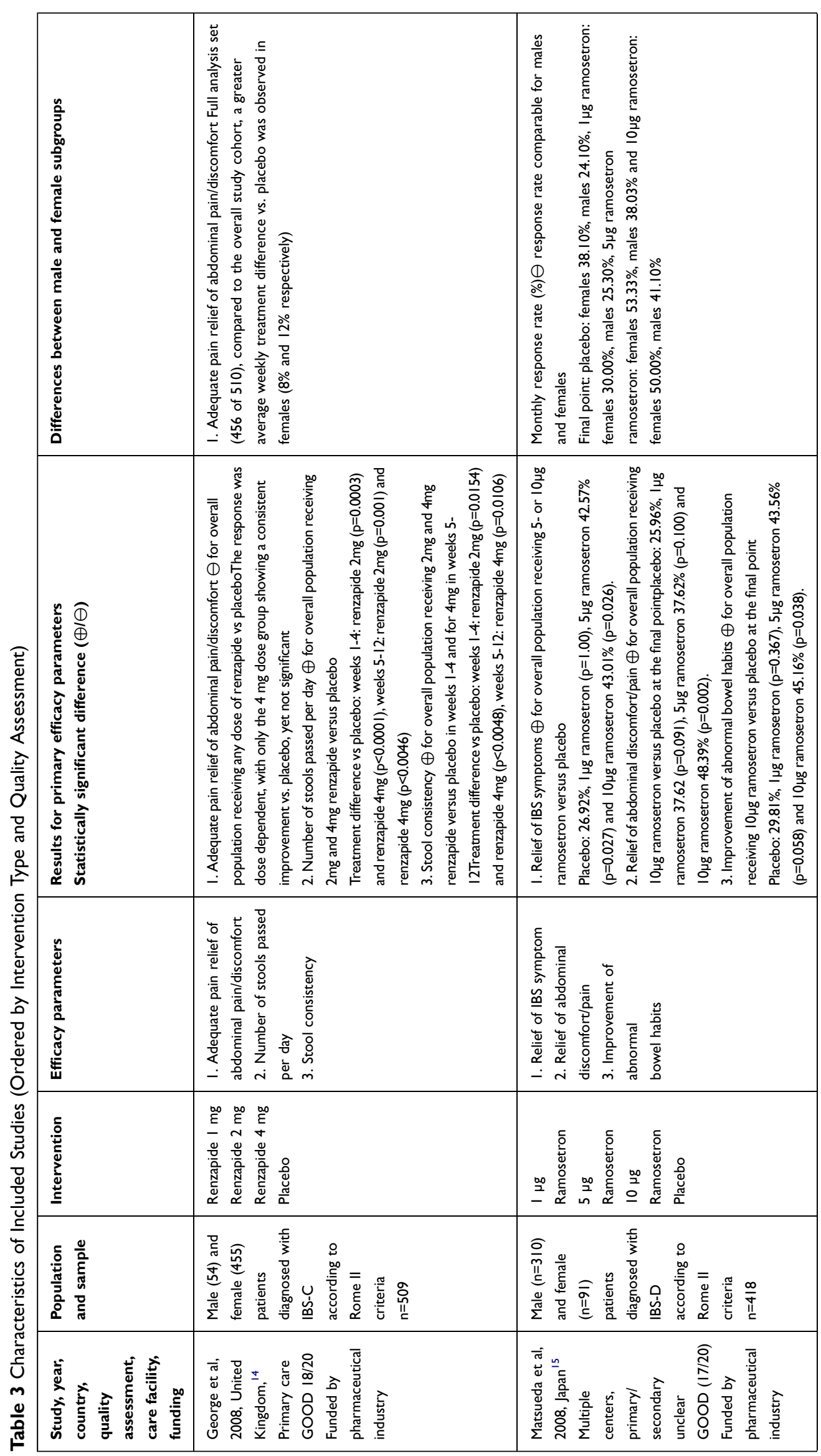




\begin{tabular}{|c|c|}
\hline 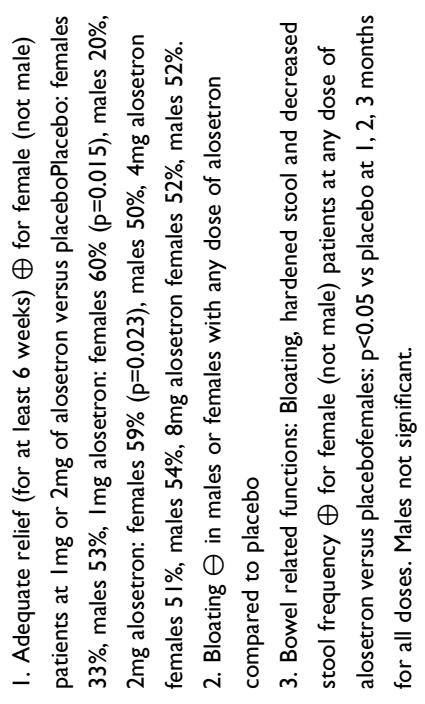 & 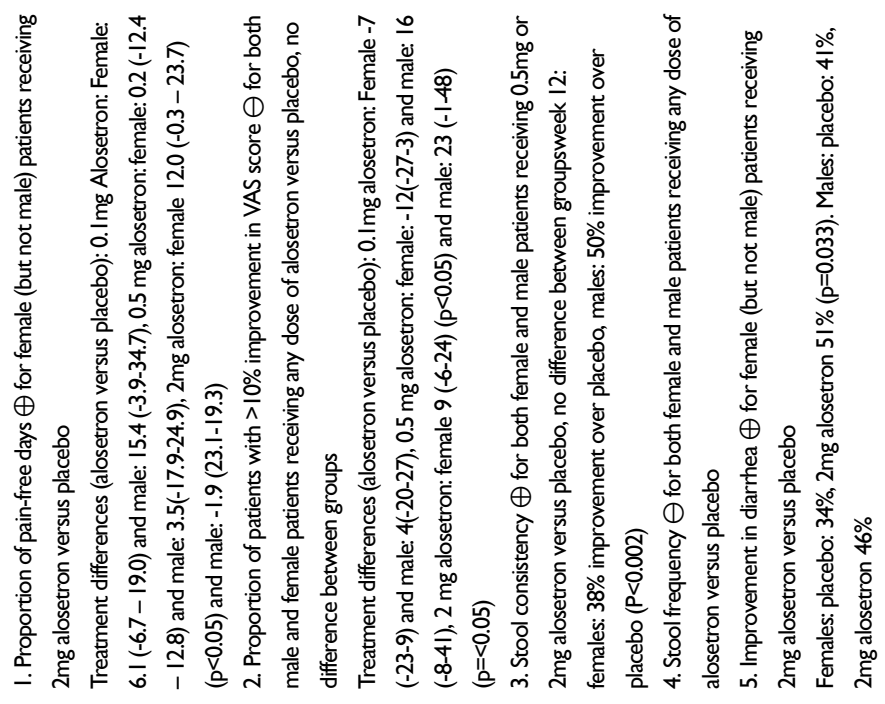 \\
\hline & 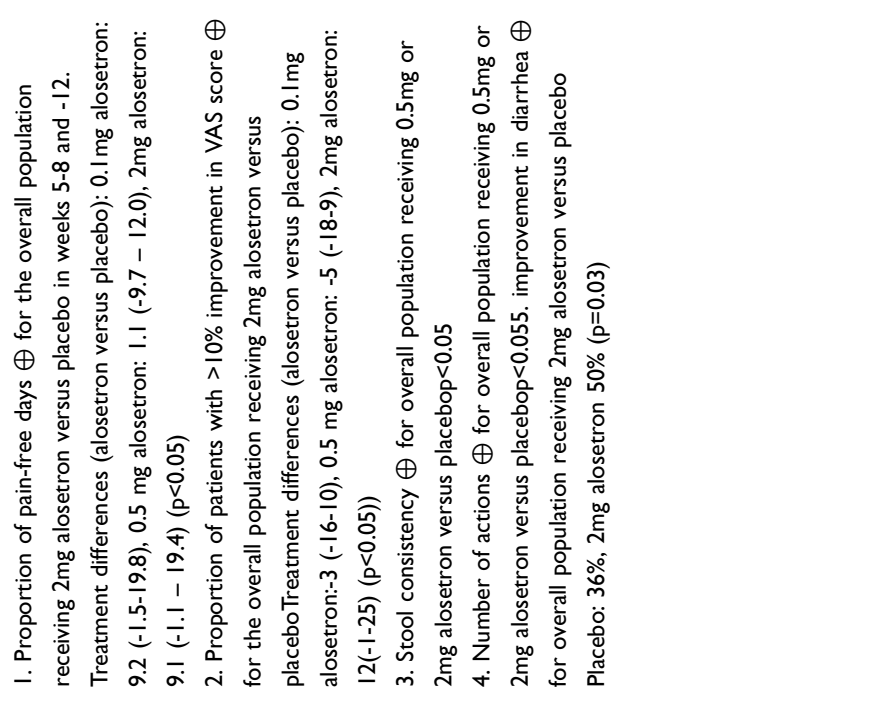 \\
\hline 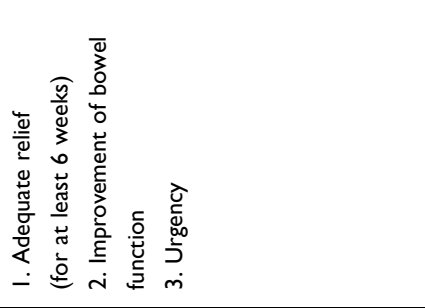 & 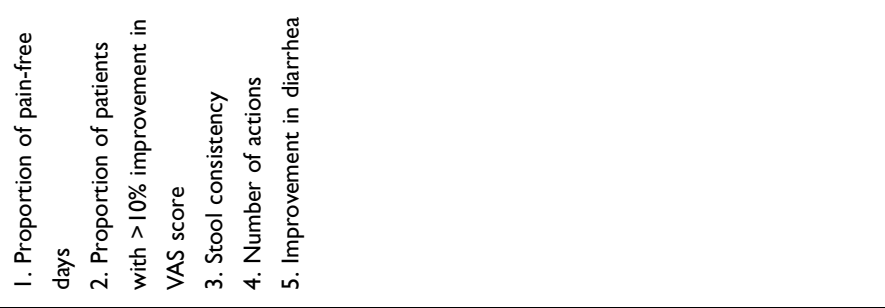 \\
\hline 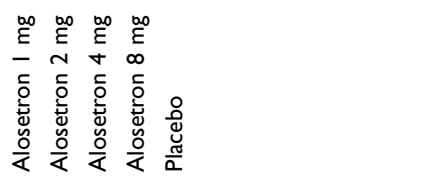 & 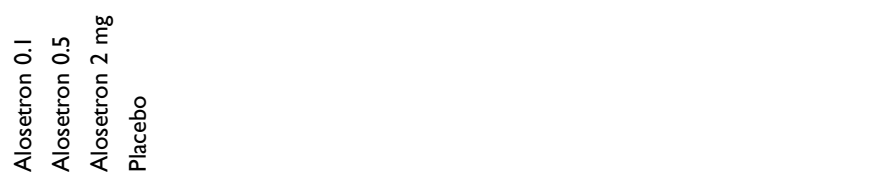 \\
\hline 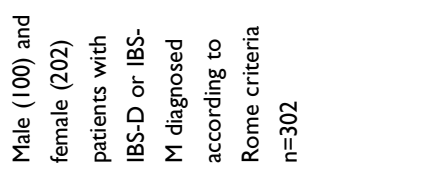 & 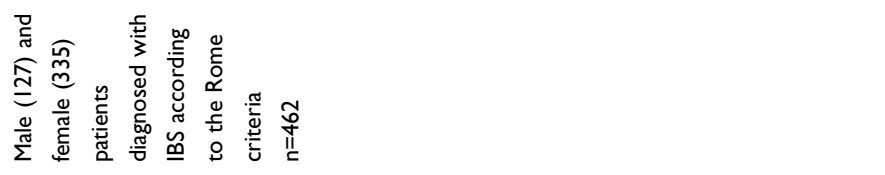 \\
\hline 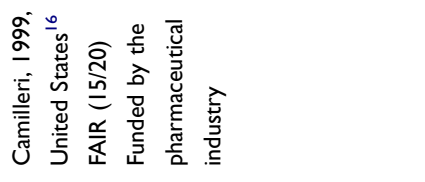 & 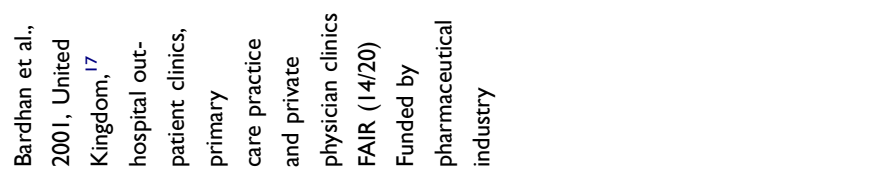 \\
\hline
\end{tabular}




\begin{tabular}{|c|c|}
\hline 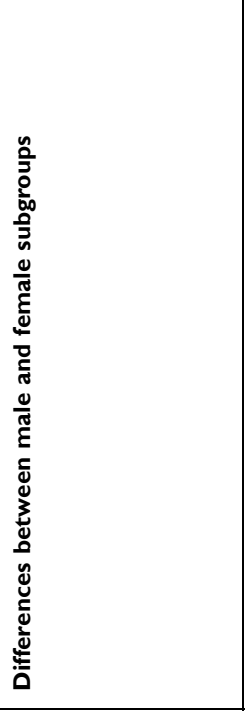 & 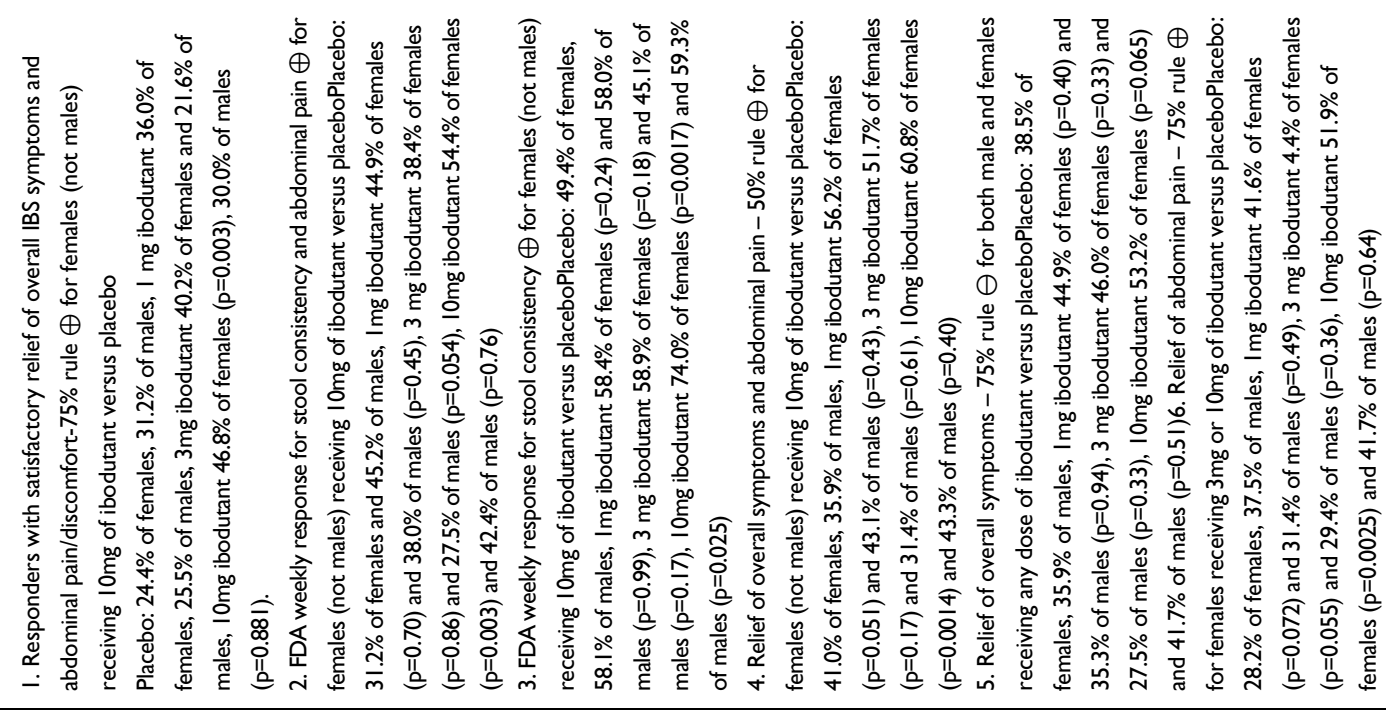 \\
\hline 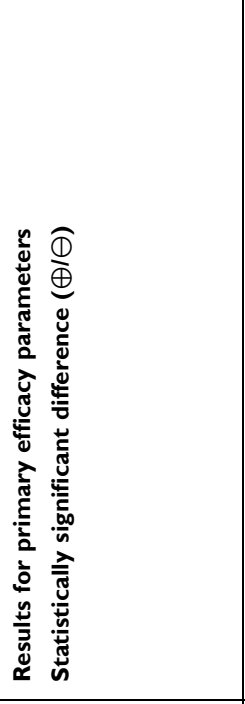 & 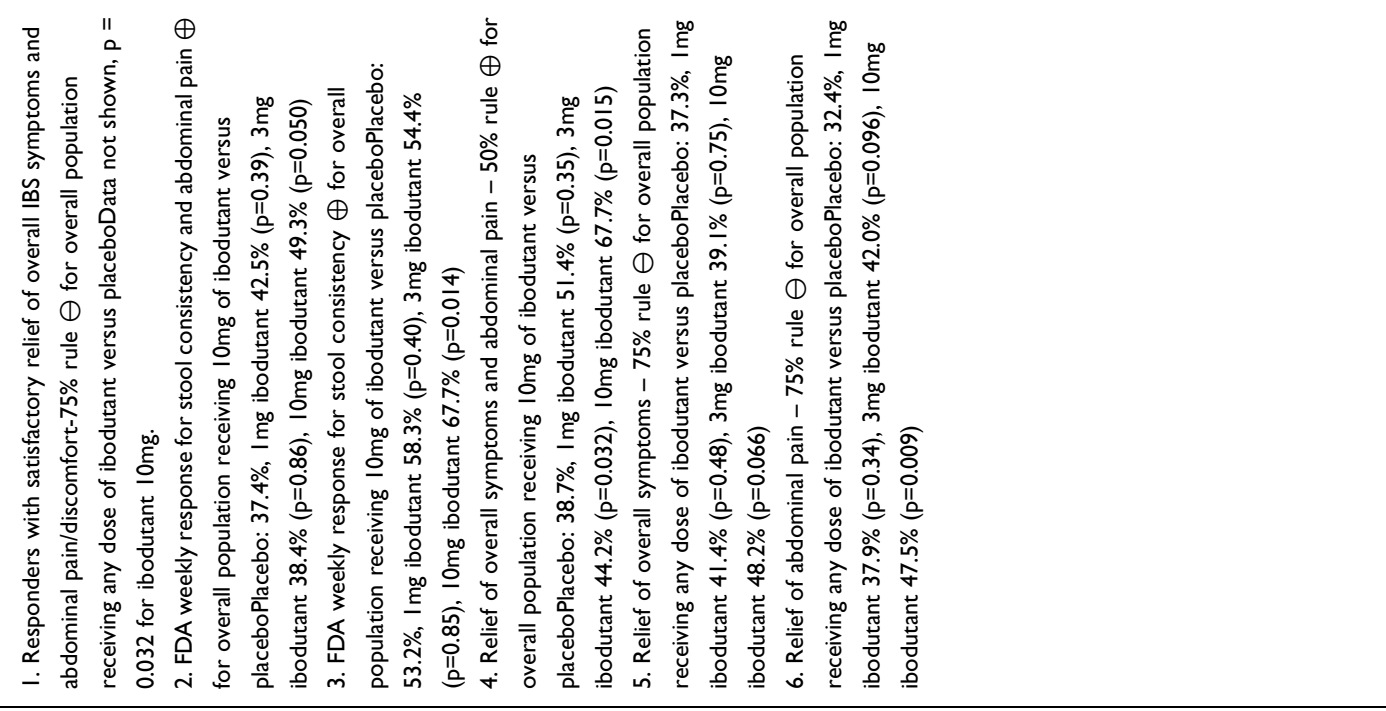 \\
\hline 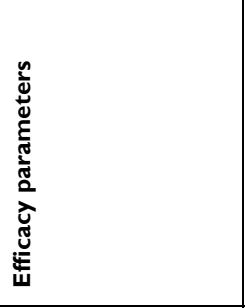 & 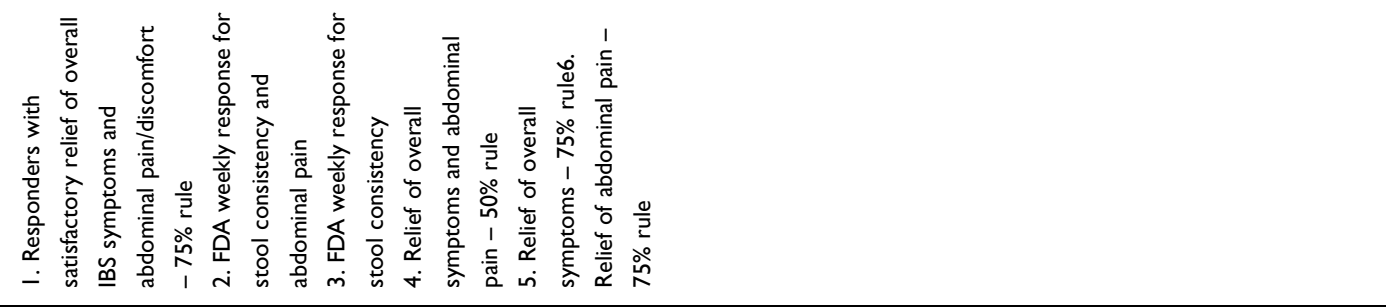 \\
\hline & 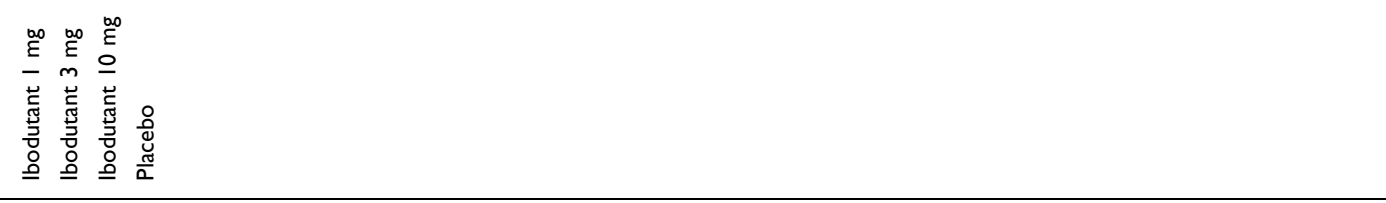 \\
\hline 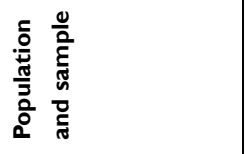 & 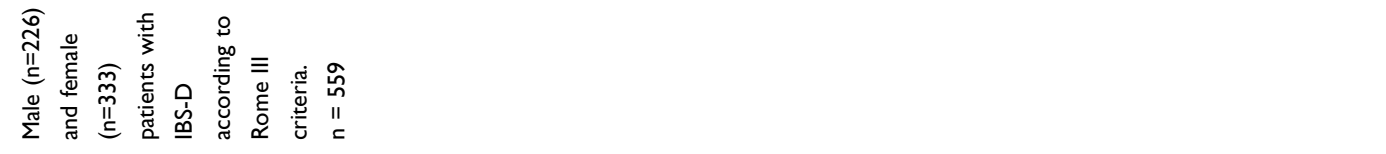 \\
\hline 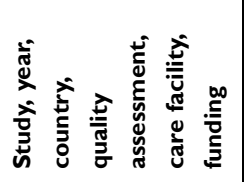 & 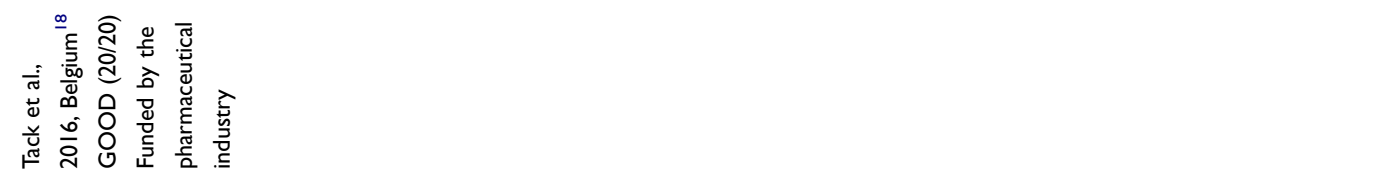 \\
\hline
\end{tabular}




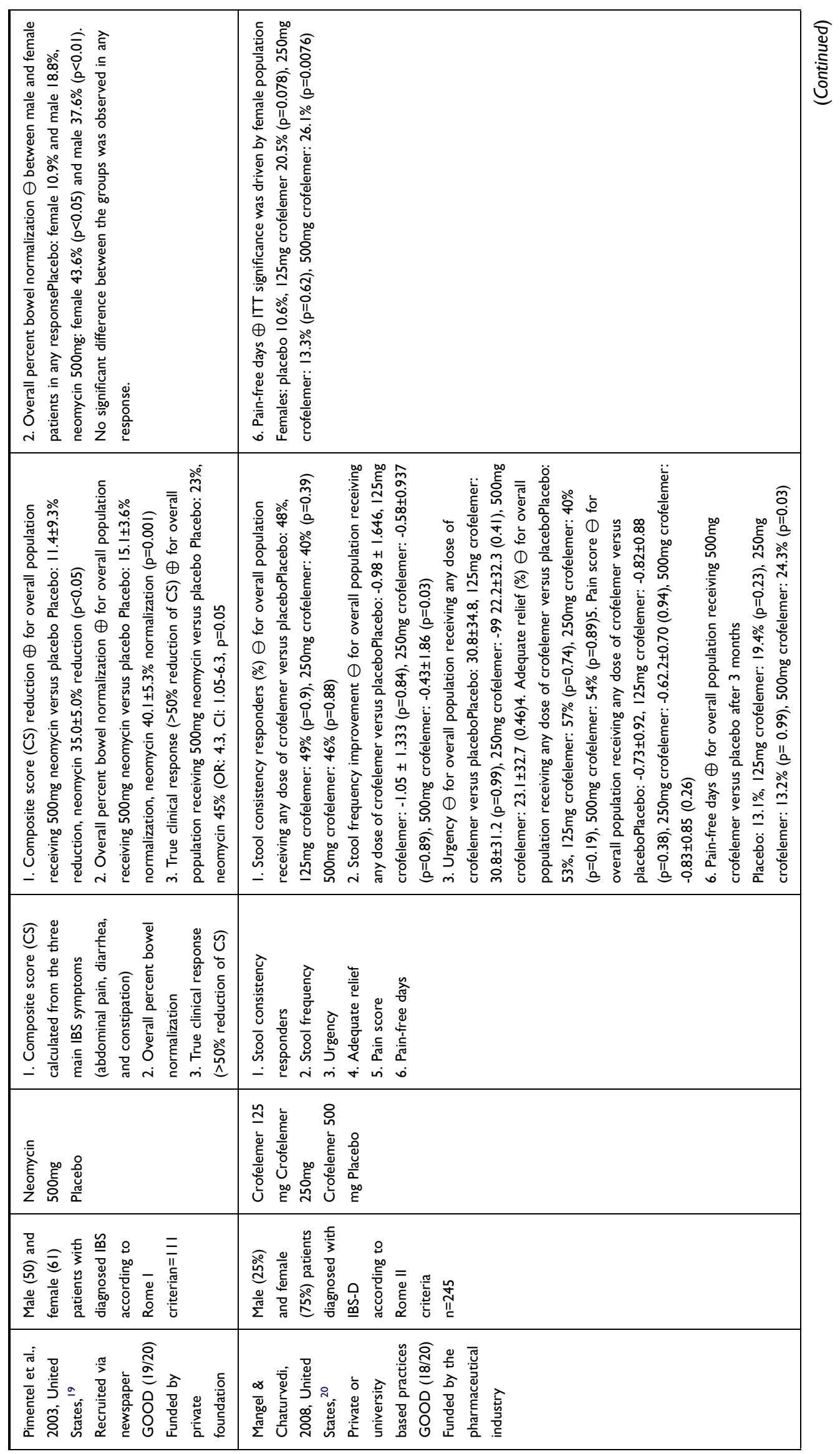




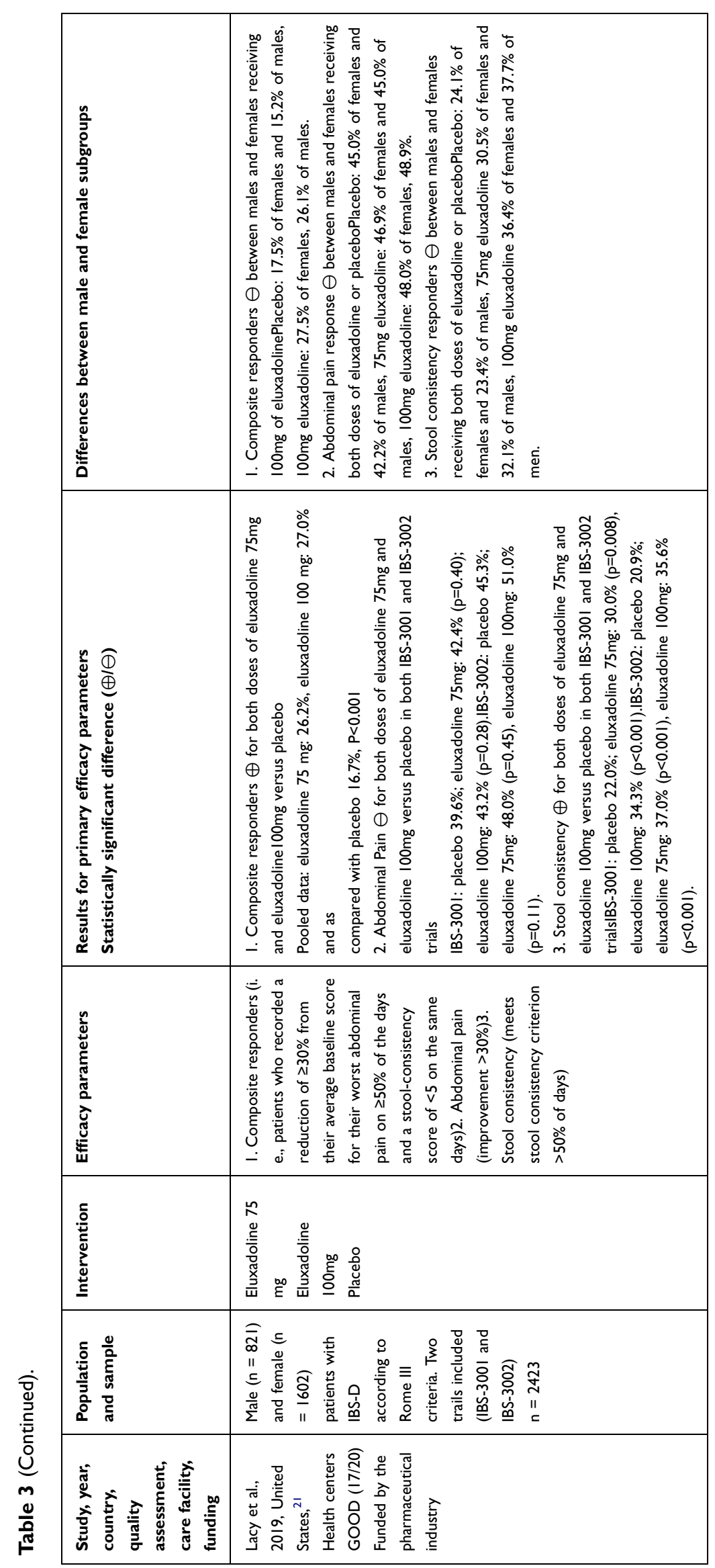




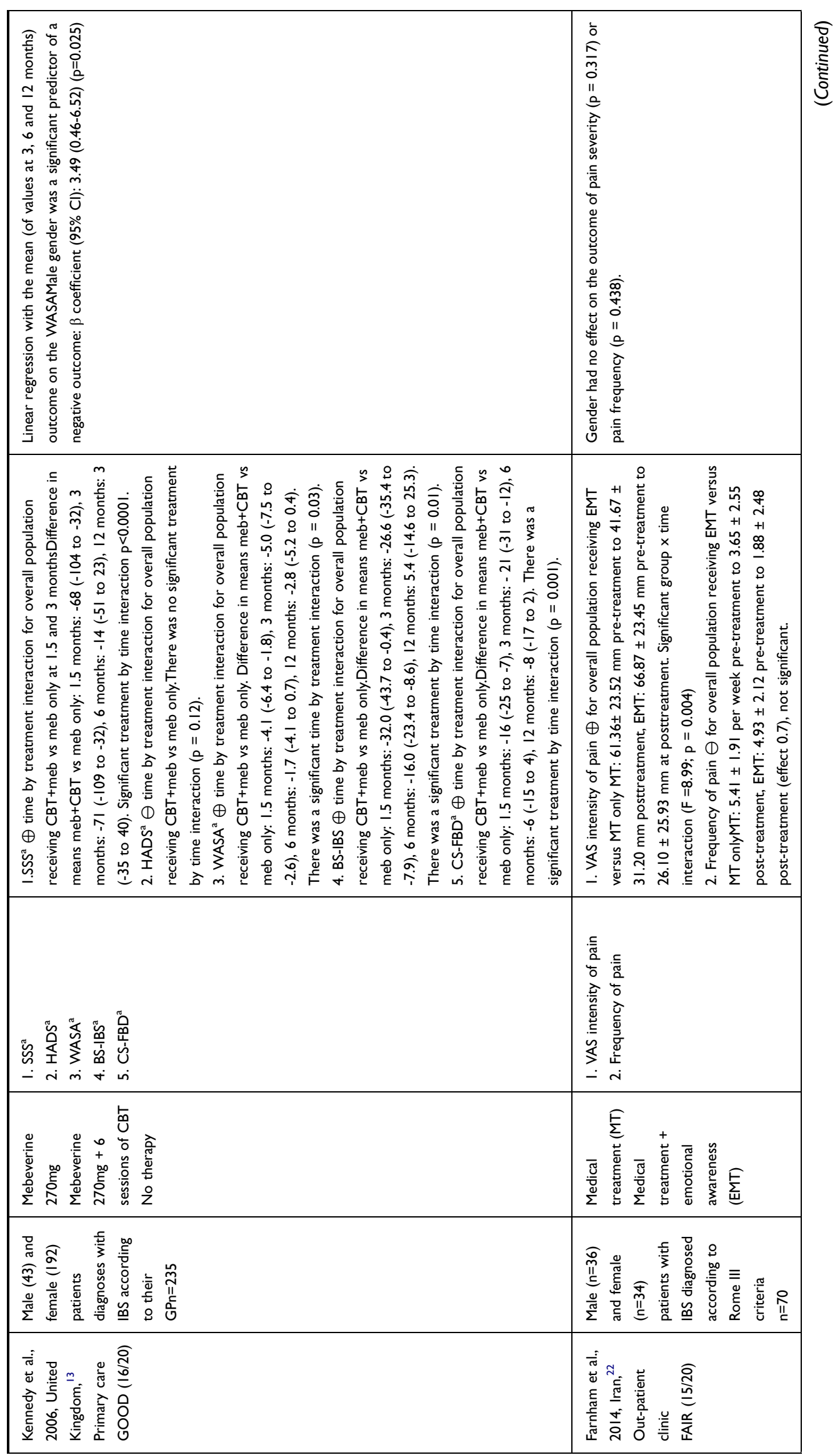




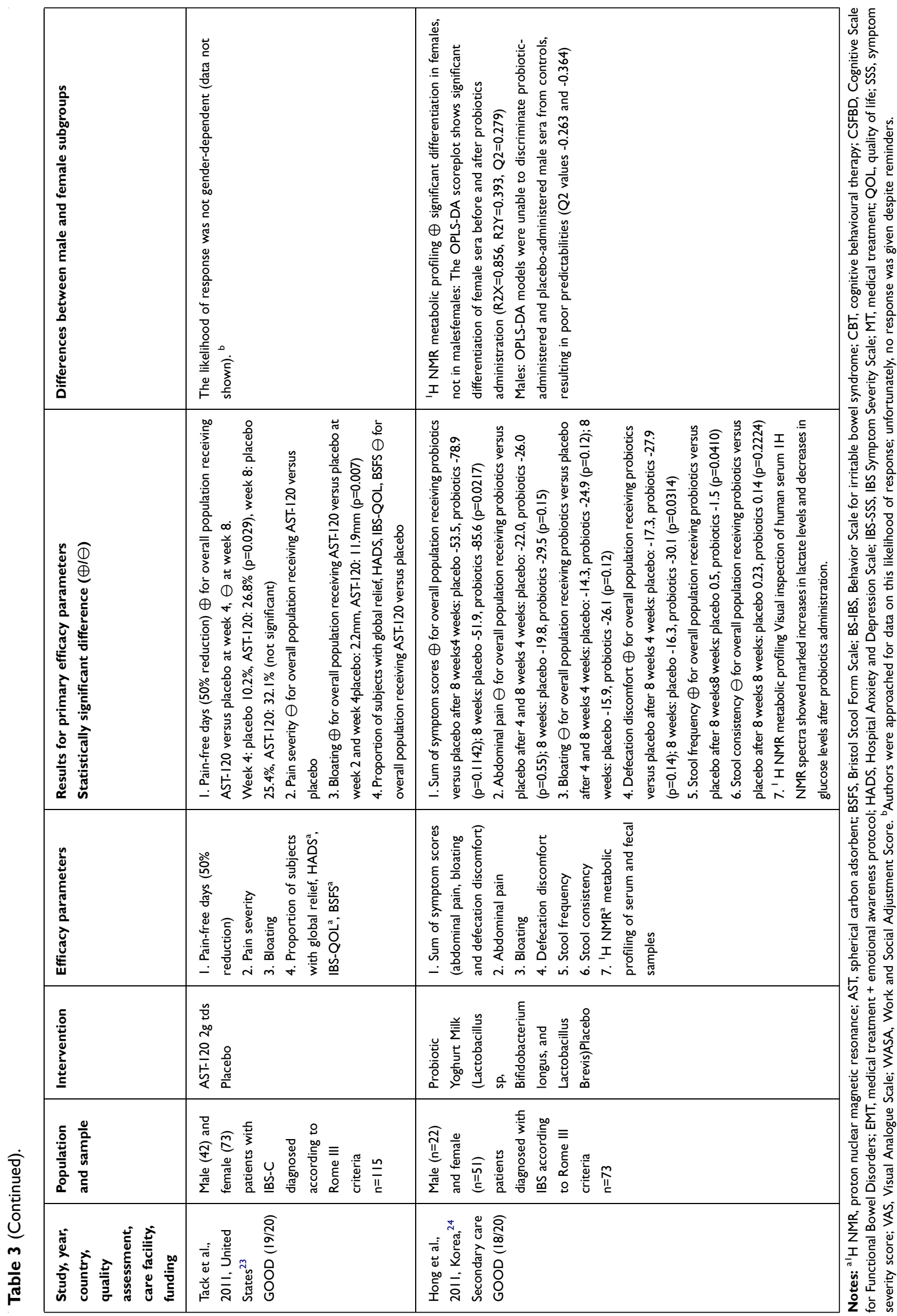


Table 4 Descriptions of Studied Pharmaceutical Interventions

\begin{tabular}{|l|l|l|}
\hline $\begin{array}{l}\text { Pharmaceutical } \\
\text { Agent }\end{array}$ & Description & Used in Article \\
\hline lbodutant & A selective neurokinin-2 (NK2) receptor antagonist. & Tack et al $^{18}$ \\
\hline Neomycin & An aminoglycoside antibiotic. & Pimentel et al $^{19}$ \\
\hline Crofelemer & $\begin{array}{l}\text { Inhibits cAMP-mediated chloride ion secretion in Caco-2 and T84 cells, and therefore has } \\
\text { antisecretory activity. }\end{array}$ & Mangel et al $^{20}$ \\
\hline Eluxadoline & $\begin{array}{l}\text { A mixed } \mu \text { - and } \text {-opioid receptor agonist and } \delta \text {-opioid receptor antagonist, that acts locally in the } \\
\text { enteric nervous system, possibly decreasing adverse effects on the central nervous system. }\end{array}$ & Lacy et al $^{21}$ \\
\hline Renzapide & $\begin{array}{l}\text { A benzamide derivative with not only 5-HT4 receptor full agonist properties, but also 5-HT3 } \\
\text { receptor antagonist properties. }\end{array}$ & George et al $^{14}$ \\
\hline $\begin{array}{l}\text { Ramosetron } \\
\text { hydrochloride }\end{array}$ & A potent and selective synthetic 5-HT 3 receptor antagonist. & Matsueda et al $^{15}$ \\
\hline Alosetron & A potent, highly selective 5-HT3 receptor antagonist. & $\begin{array}{l}\text { Bardhan et al. }^{17} \\
\text { Camilleri et al. }^{16}\end{array}$ \\
\hline
\end{tabular}

Table 5 Descriptions of Studied Psychological and Alternative Interventions

\begin{tabular}{|l|l|l|}
\hline $\begin{array}{l}\text { Psychological } \\
\text { Intervention }\end{array}$ & Description & $\begin{array}{l}\text { Used in } \\
\text { Article }\end{array}$ \\
\hline CGT & $\begin{array}{l}\text { Cognitive behavioral therapy: a talking therapy that can help you manage your problems by changing the } \\
\text { way you think and behave. }\end{array}$ & Kennedy et al. ${ }^{13}$ \\
\hline EMT & $\begin{array}{l}\text { Emotional awareness training in addition to medical treatment: a method of increasing the level of } \\
\text { conscious awareness of emotions in patients with IBS. }\end{array}$ & Farnam et al. $^{22}$ \\
\hline Alternative Interventions & $\begin{array}{l}\text { Spherical carbon adsorbent is a non-absorbed, carbon-based adsorbent with adsorbing capability for } \\
\text { histamine, serotonin and other substances implicated in IBS pathogenesis. }\end{array}$ & Tack et al. ${ }^{23}$ \\
\hline AST-I20 & $\begin{array}{l}\text { Fermented milk containing 4x } 10^{9} \text { colony forming units of Lactobacillus sp. HY780I, Bifidobacterium } \\
\text { longum HY8004, and Lactobacillus brevis HY740I. }\end{array}$ & Hong et al. ${ }^{24}$ \\
\hline $\begin{array}{l}\text { Probiotic Yoghurt } \\
\text { Milk }\end{array}$
\end{tabular}

while no improvement occurred in men. There was also a significant improvement of stool consistency, relief of overall symptoms and relief of abdominal pain in female participants. All of these outcomes did not reach significance in male participants. If we look at the entire population (ie, all men and women together), no significant difference in effectiveness of ibodutant compared to placebo is seen. The study was rated good (20/20).

\section{Neomycin}

Pimentel et al studied whether a significant reduction of IBS symptoms is observed in patients receiving neomycin. ${ }^{19}$ Both male and female neomycin-treated patients had a significant improvement of their IBS-symptoms versus placebo, with no significant difference in improvement between the sexes. The study was rated $\operatorname{good}(19 / 20)$.

\section{Crofelemer}

Mangel et al concluded that female IBS-D patients receiving $500 \mathrm{mg}$ crofelemer reported an improvement of $16 \%$ increase in pain- and discomfort-free days over that seen in placebo. ${ }^{20}$ No benefit was seen in male IBS-D patients. The study was rated good (18/20).

\section{Eluxadoline}

The study by Lacy et al demonstrated that the total group of patients, male and female, receiving eluxadoline instead of placebo, had $10 \%$ more composite responders (ie, patients who recorded a reduction of 
$\geq 30 \%$ from their average baseline score for their worst abdominal pain on $\geq 50 \%$ of the days and a stool-consistency score of $<5$ on the same days), which was a significant improvement. ${ }^{21}$ Male and female patients did not differ in outcomes, nor did eluxadoline influence stool consistency significantly in either sex. The study was rated as good $(16 / 20)$.

\section{Psychological Interventions}

Table 5 displays the non-pharmaceutical interventions, sub-grouped into psychological and alternative interventions and ordered by their quality assessment score.

\section{Cognitive Behavioral Therapy (CBT)}

In the study by Kennedy et al, groups received either mebeverine and six sessions of $\mathrm{CBT}$, or mebeverine alone. Men reported to feel more disabled in their work and social life because of their IBS symptoms. On other outcomes, no sex-gender impact was mentioned. The overall population showed significant improvement of their symptoms, the longer they had received CBT. ${ }^{13}$ The study was rated good in quality assessment (17/20).

\section{Emotional Awareness Protocol}

In the study by Farnam et al, regular medical IBS treatment was compared to medical treatment with additional emotional awareness training. Gender did not have an impact on the outcome of pain severity or pain frequency. Pain severity decreased significantly the longer patients received additional emotional awareness training; for pain frequency, no significant improvement was seen in the intention-to-treat analysis. ${ }^{22}$ The study was rated fair $(15 / 20)$.

\section{Alternative Interventions}

\section{Spherical Carbon Adsorbent - 120 (AST-120)}

The study by Tack et al reported that the significant reduction of pain-free days $(50 \%$ reduction) for the overall study population receiving AST-120 versus placebo was not gender-dependent. ${ }^{23}$ The study was rated good (20/20).

\section{Probiotic Yoghurt Milk}

Hong et al reported no gender differences in IBS symptoms before or after administration of probiotics. Sum of scores on abdominal pain, bloating and defecation discomfort showed significant improvement in the overall population after 8 weeks. ${ }^{24}$ The study was rated good $(18 / 20)$.

\section{Discussion \\ Gender Differences in Effect of Intervention}

As five out of 12 RCTs found a significant difference between men and women in at least one of their measured outcomes, gender clearly matters in the effectiveness of IBS treatment. Of the investigated pharmaceutical interventions, ibodutant and crofelemer have a better effect in women with IBS-D symptoms than in men. Of the serotonin antagonists, alosetron has a positive effect on women with IBS-M or IBS-D but demonstrates no effect in men. Men show significantly worse outcomes when cognitive behavioral therapy is added to medical treatment. All of the other RCTs but one show an equal positive effect in men and women. The administration of probiotics has no significant effect whatsoever.

Finally, our study demonstrates the importance of sexdisaggregated data collection (separated for women and men) because the positive influence of treatments for either men or women would otherwise be missed. This does not only apply to IBS but to many - if not all - other diseases. If we take a look at the current COVID-19 pandemic, for example, mortality and morbidity data show that women are faring better than men in terms of severity of disease course, likelihood of hospitalization and risk of death. ${ }^{25}$ Ultimately, the hope is that this segregated data analysis could also lead to other therapeutic choices for IBS between men and women. Today, surveys already show a difference in lifestyle changes and dietary suggestions. They were more frequently prescribed in males than in females. ${ }^{26}$ Currently, alosetron is only registered for women and ramosetron only for men with severe IBS-D. Based on this review, we can support that alosetron is only effective in women, but ramosetron appears to have equally positive effects in women based on the studies we reviewed. This highlights the importance of continuing to investigate and report differences between men and women in the effectiveness of a treatment. In this way, doctors can make the most considered possible decision for a tailor-made treatment.

\section{Interpretation}

To explain the demonstrated differences between men and women in the effectiveness of IBS treatment, we have to 
consider several components that could be affected by sex and gender. First, there is a physiological sex-related component. Studies have shown differences between men and women in the effects of sex hormones, most importantly estrogen and progesterone, on bowel function, gastrointestinal transit time, the processing of pain stimuli in the central nervous system and visceral sensitivity of the gut, as well as differences in pharmacodynamics and pharmacokinetics. ${ }^{6,8}$ Second, sex-gender differences related to bowel function or pain processing may also play a role, such as stress processing and the neuroendocrine or autonomic nervous system. However, the specific link between gut motility or sensitivity and these factors has not yet been clarified. Third, gender differences in psychological factors can also play a role, such as anxiety and depression, a history of (sexual) abuse or the tendency to somatization. ${ }^{6}$

\section{Pharmaceutical Interventions}

In the pharmaceutical group, there are three drugs that demonstrate a more positive effect on women than on men. The greater effect of ibodutant could indicate differences between men and women in the pathophysiology of IBS-D, or differences between men and women in neurokinin-2 receptor expression and sensitivity. No difference in plasma levels or volume of distribution was found in previous pharmacokinetic studies with colon models. ${ }^{27}$ Faster breakdown by men, therefore, does not explain the difference, and a higher dose would not solve this lack of effect. The effect of crofelemer on IBS has hardly been investigated. In the only other study investigating crofelemer, only women with IBS-D were included and crofelemer did not significantly improve abdominal pain over placebo, nor did it improve the number of pain-free days. ${ }^{28}$ Further research, therefore, needs to be done to determine any effect of crofelemer on IBS. As regards IBS treatment with neomycin, our study shows significant improvement of IBS symptoms in both male and female patients. As the female gender is associated with Small Intestine Bacterial Overgrowth (SIBO), which in turn is thought to cause IBS symptoms, it seems plausible that women would find greater benefit in treatment targeting SIBO, such as antibiotics. ${ }^{29}$ However, it is difficult to correctly diagnose SIBO. Therefore, caution must be exercised when drawing conclusions about SIBO, and further research must be conducted.

With regard to serotonin antagonists, alosetron is the only approved 5HT-3 receptor antagonist and is it approved only for severe IBS-D in females as the effect has not been confirmed in males. Reasons to explain these observations include sex-related differences in 5HT-3 receptor expression, lower alosetron clearance in women and/or greater 5HT synthesis under the influence of alosetron in certain brain regions in male compared with female IBS patients. ${ }^{30}$ Chang and Heitkemper suggest that possible factors that influence sex-gender differences are biobehavioral responses to stress, the menstrual and hormonal cycle and different roles and emotions between men and women, resulting in a variety of physiological and clinical responses. ${ }^{6}$ How these factors influence the response to the 5HT-3 receptor antagonist in men and women is not yet clear. Furthermore, ramosetron only works on peripheral tissues, whereas alosetron is reported to be transferred to the brain. It can be suggested that this difference in the site of action between alosetron and ramosetron contributes to the gender-related differences in responses to 5HT-3 receptor antagonists. However, further study is needed to ascertain the possibility that sex-gender differences such as site of action, menstrual and hormonal cycle and different roles and emotions between men and women are crucial factors in the response to (pharmaceutical) treatment.

\section{Psychological Interventions}

As IBS is considered a functional syndrome, somatization is an essential factor. Somatization can be described as the tendency to express psychological problems in somatic biological rather than emotional ways. A personality trait more commonly seen in somatizing patients is alexithymia, which is expressed as difficulty experiencing, expressing and describing emotional responses, and which is more common in men than women. ${ }^{31,32}$ By training emotional awareness, an attempt is made to create awareness, to reduce internalization of emotions and to deal with psychological stress in a different way. As alexithymia is more prevalent in men than in women, the effect of emotional awareness training would be expected to be greater in men. That this is not the case in the study by Farnam et al may be due to the fact that the personality trait of alexithymia is more common in patients with IBS anyway. ${ }^{32}$ Another explanation is that men do not necessarily have more difficulty with the recognition and awareness of emotions, but rather with their expression. ${ }^{33}$ As emotional awareness training does not cover this, it will not have the expected impact.

The only described difference between men and women after CBT treatment was the score for work and 
social adjustment, expressing how disabling IBS symptoms are in work and private activities. Male gender is a significant predictor of a poor outcome on this score, meaning men feel more disabled in their work and social life because of their IBS symptoms. One of the reasons for this might be that men experience diarrhea more often as their main symptom, ${ }^{5}$ which may be more bothersome in a work environment than constipation. The fact that no other differences are found between men and women receiving CBT is noteworthy as previous studies into the effect of CBT have shown women to report higher commitment to and stronger belief in the helpfulness of therapy. ${ }^{34}$

\section{Alternative Interventions}

The response to $A S T-120$ was reported not to be genderdependent. This is noteworthy because AST-120 absorbs mast cell-derived mediators and thus prevents sensitization of nociceptors in the intestinal mucosa, reducing abdominal pain and discomfort. ${ }^{35}$ As an increased level of mast cells is observed in female patients with IBS, it would seem rational to expect $A S T-120$ to have a more positive effect in women than in men. ${ }^{36}$ It would be interesting for future research, therefore, to focus on why this more positive effect for women is not found. In a probiotics study, only differences in ${ }^{1} \mathrm{H}$ NMR metabolic profiling of serum and fecal samples were analyzed separately for men and women, without elaborating on gender differences in IBS symptoms. It would be interesting, though, to examine whether this is the case, since, as we said before, the female gender is associated with SIBO and might experience a more positive effect from probiotics targeting this overgrowth. Recent studies into probiotics with different Lactobacillus species show that female subjects, particularly of the IBS-D subtype, have good response in terms of stool frequency and consistency, and show improvement of symptoms and quality of life. ${ }^{37}$

\section{Strengths and Limitations}

In this article, we have chosen to only look at articles that have included both men and women. We have therefore not discussed any articles that found a (beneficial) effect in one of the sexes, but did not look at the effect in the other sex. We also excluded studies in which both men and women were included, but in which the data were not analyzed in a segregated manner. This rules out many studies (RCTs), which immediately reveals part of the problem for which this article aims to raise awareness: often insufficient attention is paid to gender as an influencing factor on the effectiveness of treatment.

In general, most studies included a small sample size of male IBS patients. Although the total sample size had enough power as required by the quality assessment criterion, some studies report that the male subgroup is too small to draw conclusions about the effect on men. Due to this lack of power for the male subgroups, chances of finding significant differences between the intervention and the placebo are small, leaving a blind spot, therefore, in the treatment effectiveness in men with IBS. This warrants a cautious interpretation of the observed results. The risk of publication bias and incomplete literature retrieval cannot be completely ruled out. We have sought to mitigate this risk with a broad search strategy. We have decided not to include separate terms in our search strategy for the different subtypes of IBS. We do not expect to have missed any studies, because these will also fall under the umbrella term, but of this, we cannot be completely certain. It is also important to note that most studies were subsidized and executed by the pharmaceutical company that also produces the drug. ${ }^{15,16,18,20,21,23}$ Research shows that studies sponsored by pharmaceutical companies are more likely to find outcomes that benefit the sponsor than studies that are not and that there is a significant publication bias for such studies. ${ }^{38}$ Such pharmaceutical funding should be kept in mind when interpreting the observed results.

In addition, we searched meta-analyses for randomized controlled trials we might have missed. The strengths of this study are its inclusion of randomized controlled trials only and its rigorous quality assessment procedure, ensuring the best possible quality of the included trials.

In the case of IBS, future research can be conducted to explore possible gender differences in pro- or antibiotics, and head-to-head trials comparing different types of 5HT-3 antagonists should be conducted to assess possible differences in effectiveness and tolerability and the underlying mechanism of mast cells and possible therapeutic options.

\section{Conclusion}

The main conclusion of our study is to emphasize that the sex-gender factor can be a determining one in the effectiveness of IBS treatment. Our study shows that differences in responsiveness can be so great that, while the entire population shows no significant improvement, a subgroup of male or female patients does. Future research into IBS treatments should not only segregate on the basis of sex, but also on the basis of IBS subtype within sex, so that no bias can arise. 
This way firmer recommendations can be made concerning treatment. Due to the limited number of studies per treatment option, and because some studies included all types of IBS, no strong recommendations can be made on the choice of treatment in this review. The fact that only a limited number of studies remained, due to the limited number of studies looking at gender differences per drug, immediately reveals part of the problem for which this article aims to raise awareness: often insufficient attention is paid to gender as an influencing, maybe even determining factor, on the effectiveness of treatment.

Drawing a broader conclusion, we propose that an adequate number of men and women should always be included in future research. In order to ensure the reliability and assess the potential health benefits and risks for both men and women regarding risk factors, disease management, treatment and side effects, patients should be included in studies and data should be analyzed and described on the basis of sex.

\section{Acknowledgments}

The authors would like to thank Mrs. Yang, information specialist at the Radboud University Medical Centre Nijmegen in the Netherlands, for her contribution in developing the search strategy. We would also like to thank $\mathrm{Mr}$. J. Wijma, medical student at the RadboudUMC Nijmegen, for his contribution to the quality assessment procedure.

\section{Funding}

The authors received no financial support for the research, authorship and/or publication of this article.

\section{Disclosure}

The authors declare no potential conflicts of interest with respect to the research, authorship and/or publication of this article.

\section{References}

1. Canavan C, West J, Card T. The epidemiology of irritable bowel syndrome. Clin Epidemiol. 2014;6:71-80. doi:10.2147/CLEP.S40245

2. Chey WD, Kurlander J, Eswaran S. Irritable bowel syndrome: a clinical review. JAMA. 2015;313(9):949-958. doi:10.1001/jama.2015. 0954

3. Drossman DA, Camilleri M, Mayer EA, Whitehead WE. AGA technical review on irritable bowel syndrome. Gastroenterology. 2002;123 (6):2108-2131.

4. Kim YS, Kim N. Sex-gender differences in irritable bowel syndrome. $J$ Neurogastroenterol Motil. 2018;24(4):544-558. doi:10.5056/jnm 18082
5. Lee OY, Mayer EA, Schmulson M, Chang L, Naliboff B. Genderrelated differences in IBS symptoms. Am J Gastroenterol. 2001;96 (7):2184-2193. doi:10.1111/j.1572-0241.2001.03961.x

6. Chang L, Heitkemper MM. Gender differences in irritable bowel syndrome. Gastroenterology. 2002;123(5):1686-1701. doi:10.1053/ gast.2002.36603

7. Vemuri R, Sylvia KE, Klein SL, et al. The microgenderome revealed: sex differences in bidirectional interactions between the microbiota, hormones, immunity and disease susceptibility. Semin Immunopathol. 2019;41(2):265-275. doi:10.1007/s00281-018-0716-7

8. Soldin OP, Mattison DR. Sex differences in pharmacokinetics and pharmacodynamics. Clin Pharmacokinet. 2009;48(3):143-157. doi:10.2165/00003088-200948030-00001

9. Hungin AP, Chang L, Locke GR, Dennis EH, Barghout V. Irritable bowel syndrome in the United States: prevalence, symptom patterns and impact. Aliment Pharmacol Ther. 2005;21(11):1365-1375. doi:10.1111/j.1365-2036.2005.02463.x

10. Lagro-Janssen T. Gender, equality and medicine 2013:48.

11. NIoH N. Quality assessment of controlled intervention studies. Systematic evidence reviews and clinical practice guidelines; 2014. Available from: www.nhlbi.nih.gov/health-topics/study-quality-assess ment-tools. Accessed February 6, 2021.

12. Higgins JP, Altman DG, Gøtzsche PC, et al. The cochrane collaboration's tool for assessing risk of bias in randomised trials. BMJ. 2011;343(oct18 2):d5928. doi:10.1136/bmj.d5928

13. Kennedy TM, Chalder T, McCrone P, et al. Cognitive behavioural therapy in addition to antispasmodic therapy for irritable bowel syndrome in primary care: randomised controlled trial. Health Technol Assess. 2006;10(19):iii-iv, ix-x, 1-67. doi:10.3310/ hta 10190

14. George AM, Meyers NL, Hickling RI. Clinical trial: renzapride therapy for constipation-predominant irritable bowel syndrome-multicentre, randomized, placebo-controlled, double-blind study in primary healthcare setting. Aliment Pharmacol Ther. 2008;27(9):830837. doi:10.1111/j.1365-2036.2008.03649.x

15. Matsueda K, Harasawa S, Hongo M, Hiwatashi N, Sasaki D. A Phase II trial of the novel serotonin type 3 receptor antagonist ramosetron in Japanese male and female patients with diarrhea-predominant irritable bowel syndrome. Digestion. 2008;77(3-4):225-235. doi:10.1159/ 000150632

16. Camilleri M, Mayer EA, Drossman DA, et al. Improvement in pain and bowel function in female irritable bowel patients with alosetron, a 5-HT3 receptor antagonist. Aliment Pharmacol Ther. 1999;13 (9):1149-1159. doi:10.1046/j.1365-2036.1999.00610.x

17. Bardhan KD, Bodemar G, Geldof $\mathrm{H}$, et al. A double-blind, randomized, placebo-controlled dose-ranging study to evaluate the efficacy of alosetron in the treatment of irritable bowel syndrome. Aliment Pharmacol Ther. 2000;14(1):23-34. doi:10.1046/j.1365-2036.2000. 00684.x

18. Tack J, Schumacher K, Tonini G, Scartoni S, Capriati A, Maggi CA. The neurokinin-2 receptor antagonist ibodutant improves overall symptoms, abdominal pain and stool pattern in female patients in a phase II study of diarrhoea-predominant IBS. Gut. 2017;66(8):14031413. doi:10.1136/gutjnl-2015-310683

19. Pimentel M, Chow EJ, Lin HC. Normalization of lactulose breath testing correlates with symptom improvement in irritable bowel syndrome. A double-blind, randomized, placebo-controlled study. Am J Gastroenterol. 2003;98(2):412-419. doi:10.1111/j.1572-0241.2003. 07234.x

20. Mangel AW, Chaturvedi P. Evaluation of crofelemer in the treatment of diarrhea-predominant irritable bowel syndrome patients. Digestion. 2008;78(4):180-186. doi:10.1159/000185719

21. Lacy BE, Harris LA, Chang L, et al. Impact of patient and disease characteristics on the efficacy and safety of eluxadoline for IBS-D: a subgroup analysis of Phase III trials. Therap Adv Gastroenterol. 2019;12:1756284819841290. doi:10.1177/1756284819841290 
22. Farnam A, Somi MH, Farhang S, Mahdavi N, Ali Besharat M. The therapeutic effect of adding emotional awareness training to standard medical treatment for irritable bowel syndrome: a randomized clinical trial. J Psychiatr Pract. 2014;20(1):3-11. doi:10.1097/01.pra.00 00442934.38704.3a

23. Tack JF, Miner PB, Fischer L, Harris MS. Randomised clinical trial: the safety and efficacy of AST-120 in non-constipating irritable bowel syndrome - a double-blind, placebo-controlled study. Aliment Pharmacol Ther. 2011;34(8):868-877. doi:10.1111/j.1365-2036.20 11.04818.x

24. Hong YS, Hong KS, Park MH, et al. Metabonomic understanding of probiotic effects in humans with irritable bowel syndrome. J Clin Gastroenterol. 2011;45(5):415-425. doi:10.1097/MCG.0b013e3182 $07 \mathrm{f} 76 \mathrm{c}$

25. Womersley K, Ripullone K, Peters SA, Woodward M. Covid-19: male disadvantage highlights the importance of sex disaggregated data. BMJ. 2020;370:m2870. doi:10.1136/bmj.m2870

26. Bellini M, Usai-Satta P, Bove A, et al. Chronic constipation diagnosis and treatment evaluation: the "CHRO.CO.DI.T.E." study. BMC Gastroenterol. 2017;17(1):11. doi:10.1186/s12876-016-0556-7

27. Bellucci F, Buéno L, Bugianesi R, et al. Gender-related differential effect of tachykinin NK2 receptor-mediated visceral hyperalgesia in guinea pig colon. Br J Pharmacol. 2016;173(8):1329-1338. doi:10. $1111 /$ bph. 13427

28. Nee J, Salley K, Ludwig AG, et al. Randomized clinical trial: crofelemer treatment in women with diarrhea-predominant irritable bowel syndrome. Clin Transl Gastroenterol. 2019;10(12):e00110. doi:10.14 309/ctg.0000000000000110

29. Ghoshal UC, Shukla R, Ghoshal U. Small intestinal bacterial overgrowth and irritable bowel syndrome: a bridge between functional organic dichotomy. Gut Liver. 2017;11(2):196-208. doi:10.5009/ gnl16126

30. Mulak A, Taché Y. Sex difference in irritable bowel syndrome: do gonadal hormones play a role? Gastroenterol Pol. 2010;17(2):89-97.
31. Mattila AK, Kronholm E, Jula A, et al. Alexithymia and somatization in general population. Psychosom Med. 2008;70(6):716-722. doi:10. 1097/PSY.0b013e31816ffc39

32. Steinweg DL, Dallas AP, Rea WS. Fibromyalgia: unspeakable suffering, a prevalence study of alexithymia. Psychosomatics. 2011;52 (3):255-262. doi:10.1016/j.psym.2010.12.022

33. Salminen JK, Saarijärvi S, Äärelä E, Toikka T, Kauhanen J. Prevalence of alexithymia and its association with sociodemographic variables in the general population of finland. J Psychosom Res. 1999;46(1):75-82. doi:10.1016/S0022-3999(98)00053-1

34. Brown LA, Wiley JF, Wolitzky-Taylor K, et al. Changes in selfefficacy and outcome expectancy as predictors of anxiety outcomes from the CALM study. Depress Anxiety. 2014;31(8):678-689. doi:10.1002/da.22256

35. Mosińska P, Storr M, Fichna J. The role of AST-120 and proteinbound uremic toxins in irritable bowel syndrome: a therapeutic perspective. Therap Adv Gastroenterol. 2015;8(5):278-284. doi:10.11 77/1756283X15587866

36. Barbara G, Stanghellini V, De Giorgio R, et al. Activated mast cells in proximity to colonic nerves correlate with abdominal pain in irritable bowel syndrome. Gastroenterology. 2004;126(3):693-702. doi:10.1053/j.gastro.2003.11.055

37. Preston K, Krumian R, Hattner J, de Montigny D, Stewart M, Gaddam S. Lactobacillus acidophilus CL1285, Lactobacillus casei LBC80R and Lactobacillus rhamnosus CLR2 improve quality-oflife and IBS symptoms: a double-blind, randomised, placebo-controlled study. Benef Microbes. 2018;9(5):697-706. doi:10.3920/BM 2017.0105

38. Lexchin J, Bero LA, Djulbegovic B, Clark O. Pharmaceutical industry sponsorship and research outcome and quality: systematic review. BMJ. 2003;326(7400):1167. doi:10.1136/bmj.326.7400.1167
International Journal of General Medicine

\section{Publish your work in this journal}

The International Journal of General Medicine is an international, peer-reviewed open-access journal that focuses on general and internal medicine, pathogenesis, epidemiology, diagnosis, monitoring and treatment protocols. The journal is characterized by the rapid reporting of reviews, original research and clinical studies across all disease areas. The manuscript management system is completely online and includes a very quick and fair peer-review system, which is all easy to use. Visit http://www.dovepress.com/ testimonials.php to read real quotes from published authors. 